\title{
Metabolism of Dihydroxyacetone in Rat Liver Preparations
}

\author{
By Makepeace U. Tsao, Susan J. Teagan, Pal E. Borondy and James F. Hogg \\ Metabolism of dihydroxyacteone (DHA) \\ has been studied with rate liver extract. \\ Requirements for ATP, NAD and mag- \\ nesium have been quantitated. Calcium, \\ lithium and phosphate ions as well as \\ were found to inhibit DHA metabolism. \\ Formation of DHA phosphate and lac- \\ tate was demonstrated by paper chroma- \\ tography and autoradiography. Evidence \\ of a new DHA kinase is presented.
} several well known metabolic inhibitors

E ARLIER LITERATURE on the utilization of dihydroxyacetone (DHA) by the intact animal has been well documented. ${ }^{1}$ Recent work with $\mathrm{C}^{\mathbf{1 4}}$ labeled DHA shows that this triose is oxidized by the intact rat. ${ }^{2}$ In contrast to the large number of studies on utilization of DHA by man and animal, little has been reported on work with tissue preparations. Contradiction resulted from the first attempts to determine the metabolic fate of DHA in tissue preparations. ${ }^{3-5}$ Conversion of DHA to hexose in the liver slice of the rat has been reported. ${ }^{6}$ More recently, oxidative phosphorylation of DHA has been demonstrated along with a number of carbohydrates and intermediates. ${ }^{7}$ Phosphorylating enzymes with activity for trioses have also been described. ${ }^{8-10}$ However, in none of these studies was the specific measuremont of the disappearance of DHA or the identification of the product $(s)$ of the reaction made. Therefore, we have undertaken a direct approach to elucidate the metabolic fate of DHA in the liver homogenate of the rat.

In order to establish the metabolic fate of DHA, methods for the analysis of DHA were devised. ${ }^{11,12} \mathrm{C}^{14}$-labeled DHA was prepared and the over-all effect of DHA administration to intact normal and diabetic rats was observed. ${ }^{2,13}$ This paper describes our study on the influence of the other metabolites and inhibitors, identification and stochiometry of the metabolic products of DHA. From these studies, a metabolic pathway for DHA has been established.

\section{Material and Methods}

Chemicals: The chemicals used are listed below with their source; they were not further purified except the lithium and calcium salts of organic acids which were freed of cations by passing through a Dowex-50 $(\mathrm{H}+)$ column. Dihydroxyacetone (Aldrich Chemical Co., Inc.), dihydroxyacetone phosphate (California Corporation for Biochemical Research), NAD (Nutritional Biochemical Co.), glucose and inorganic chemicals (Mallinckrodt Chemical Works), iodoacetic acid and sodium EDTA (Distillation Products), lithium hydroxypyruvate ( $\mathrm{K} \& \mathrm{~K}$ Laboratories), sodium lactate-1-C14 (Nuclear Chicago Corp.). Those chemicals not listed here were obtained from Sigma Chemical Co. DHA-1, 3-C14 was synthesized as described previously. ${ }^{2}$

From Department of Pediatrics and Communicable Diseases and Department of Biological Chemistry, University of Michigan, Ann Arbor, Michigan.

This work was supported by grant AM-5152 from the Public Health Service.

Received for publication Aug. 6, 1964. 


\section{Procedures}

Tissuc preparation: Male Spraguc-Dawley rats weighing 250 to $400 \mathrm{Gm}$. were killed by decapitation. The liver was removed, immediately weighed and rinsed in cold buffer of pH 7.4 which contained $0.01 M$ sodim phosphate and $0.001 M$ sodium EDTA. The tissue homogenate was prepared by mincing and homogenizing the tissue in 1.5 times its weight of this buffer in a Potter-Elvehjem homogenizer. Liver extracts were prepared by centrifuging the homogenate at $1.05 \times 105 \times \mathrm{x}$ for 1 hour in the cold and collecting the clear supernatant. For the fractionation of liver eell components a standard procedure was used. 14

Measurement of DIIA utilization rate: The general procedure for the study of DHA utilization by the liver homogenate or extract was based on the disappearance of DHA upon incubation with the tissue preparation and is described as follows. A cold incubation mixture containing $0.05 \mathrm{ml}$. of NAD solution $(0.03 \mathrm{M}), 0.0 .5 \mathrm{ml}$. of ATP $(0.02 M), 5 \mu \mathrm{l}$. of magnesium sulfate $(0.154 \mathrm{M}), 0.65 \mathrm{ml}$. of tissue preparation, and $0.25 \mathrm{ml}$. of phosphatr buffer (0.01 $M, \mathrm{pH} 6.9$ ) was warmed to $37 \mathrm{C}$. At zero time $50 \mu \mathrm{l}$. of a DHA solution $(0.2 M)$ was added and immediately after quick mixing, a sample was removed and its proteins were precipitated. Thereafter, additional samples were romoved at 5,10 or 20 minutes. All procedures were done in duplicate. The DHA content of samples was masured by a modification of a method developed in this laboratory; 12 metaphosphoric acid $(0.2 M)$ was used for the precipitation of proteins instead of harjum hydroxide and zinc sulfate.

When the amount of liver extract in the incubation mixture was varied with simultaneous adjustment of the volume of the buffer to maintain the total volume, a linear relationship, was found between the rate of DHA disappearance and the amount of extract.

(Other procedures: The lactate levels were determined by a colorimetric procedure. ${ }^{15}$ Interference from known amounts of DHA, although small, was corrected by calculation. For two-dimensional paper chromatography, Whatman $3 \mathrm{MM}$ filter paper $20 \times 20 \mathrm{~cm}$. was used. The solvent systems were (1) phenol, $450 \mathrm{Gm}$ : water, $150 \mathrm{ml}$; and formic atcil, $12 \mathrm{ml}$ : (2) mix immediately before using the following 2 solutions, (a) butanol, 62:3 $\mathrm{ml}$ : and water, $42 \mathrm{ml}$; and (b) propionic acid, $310 \mathrm{ml}$; and water, $395 \mathrm{ml} .{ }^{16}$ For onedimensional chromatography, the solvent systems cmployed were as follows; (1) butanol, acetic acid and water; (2) ethanol, ammonia and water. ${ }^{1 \tau}$ Two $x$-ray films ( $8 \times 10$ in. Eastman No Screen Medical) were placed against the developed and dried paper (hromatogram for 7 days in order to detect the radioactive spots. To visualize the loci of reducing substances on the paper chromatograms, a mixture containing $9 \mathrm{Gm}$. phthalic acid, $425 \mathrm{ml}$. butanol. $50 \mathrm{ml}$. water, $25 \mathrm{ml} .95$ per cent ethanol and $5 \mathrm{ml}$ aniline ${ }^{18}$ was sprayed on the palper and followed by 10 minutes heating at $100 \mathrm{C}$. The acid production during incubation was measured by titration with $0.200 N$ sodiun hydroxide through a micro burct to maintain a constant $\mathrm{pH}$ as monitored with a micro glass electrode and a Beckman Zeromatic $\mathrm{pH}$ meter. The production of CO.. by an incubation mixture was determined with Conway diffusion cells. ${ }^{19}$

\section{REsuLts}

Effect of the presence of metabolites and intermediates: To incubation mixtures containing all the components described under Procedure were added concentrations of the following substances equimolar to that of DHA: glucose, fructose, glucose-1-phosphate, glucose-6-phosphate, fructose-6-phosphate, fructose -1, 6-diphosphate, 3-phosphoglycerate, hydroxypyruvate, glycerate and glycerol. Excepting a moderate inhibition of DHA metabolism by fructose-6phosphate, their presence had no significant effect. The concentrations of all of these substances were then increased tenfold in order to intensify whatever effect they might have on DHA metabolism. Again there was no effect except an 88 per cent inhibition by the fructose-6-phosphate. 
Table 1.-Inhibitors of DHA Metabolism

\begin{tabular}{|c|c|c|c|}
\hline \multicolumn{4}{|c|}{$\begin{array}{l}\text { Relative DHA Disappearance Rate during } 10 \text { Minutes } \\
\text { Incubation Time with Control as } 100\end{array}$} \\
\hline & $10^{-:} M$ & $10^{-i M} M$ & $10^{-4} M$ \\
\hline Arsenate & 0 & 55 & 116 \\
\hline Chloromercuribenzoate & 0 & 43 & 100 \\
\hline Fluoride & 0 & 42 & 103 \\
\hline Iodacetate & 0 & 78 & 86 \\
\hline
\end{tabular}

Inhibitors: The effects of several well known inhibitors on DHA metabolism were determined when they were added in various concentrations to the incubation mixture. The results are summarized in table 1 . In addition, phosphate at $0.1 \mathrm{M}$ exerted 100 per cent inhibition; at $0.05 \mathrm{M} 87$ per cent inhibition; at $0.005 M$ no inhibition. Calcium ions at $0.005 M$ caused 100 per cent inhibition; at $0.002 M 23$ per cent inhibition; and at $0.001 M$ no inhibition. Lithium ions at $0.008 \mathrm{M}$ showed a 61 per cent inhibition. Tris buffer at 0.02 $M$ effected a 20 per cent inhibition.

Distribution of activity among cell components: Liver cell components were prepared and kept frozen in $0.25 \mathrm{M}$ sucrose solution at $-20 \mathrm{C}$. The freshly thawed and resuspended material was used without further disruption of the particles. The distribution of the activity for DHA metabolism was measured by substituting a suspension of cell components for homogenate and determining the DHA disappearance rate. The activity of each component in terms of per cent of the total was as follows: supernatant, 87 per cent; microsomes, 7 per cent; mitochondria, 0 per cent, and nuclei (plus debris), 6 per cent.

Products of DHA metabolism in liver extract: Apparently considerable amounts of readily ionizable acid were produced during incubation becausc the $\mathrm{pH}$ decreased even when maximum permissible concentration of the phosphate buffer was used. In the measurement of acid production, a preincubation period of 15 minutes was allowed for the exhaustion of endogenous substances in the liver extract that might yield acid upon their metabolic conversion. Thus, the acid production due to DHA metabolism would not be masked by this endogenous process. Five times the usual amount of incubation mixtures was employed to permit removal of samples at 5 and 10 minutes without unduly affecting the experimental conditions. The DHA levels in these samples were determined to give the amount of DHA metabolized. The results are shown in table 2.

Since the most likely acid product from DHA metabolism is lactic acid, the lactate concentration at the beginning and the end of 10 minutes incubation was measured. Preincubated mixtures were again used to minimize the error due to endogenous lactate production. The disappearance of DHA was also determined. In one experiment ATP was omitted from the incubation mixture. A stochiometric relationship between DHA disappeared and lactate produced was found. In another experiment in which ATP was added to augment the endogenous cofactor, such relationship was not obtained (table 3 ). 
Table 2.-Acid Production from DHA Metabolism

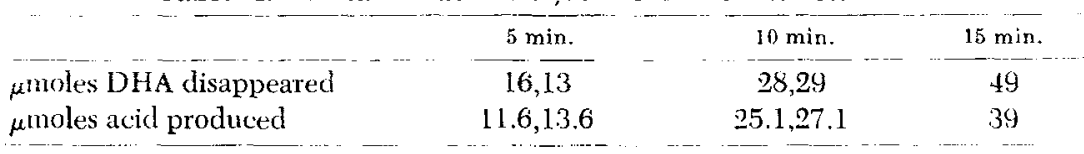

Table 3.-Lactate Production from DHA Metabolism

\begin{tabular}{|c|c|c|c|c|c|}
\hline \multirow{3}{*}{$\begin{array}{l}\mu \text { moles DHA disappeared } \\
\mu \text { moles lactate formed }\end{array}$} & \multicolumn{2}{|c|}{ No Added ATP } & & \multicolumn{2}{|c|}{ ATP Added } \\
\hline & 5.6 & 6.7 & & 9.4 & 10.0 \\
\hline & 5.67 & 6.88 & & 8.59 & 9.47 \\
\hline
\end{tabular}

To establish that the lactate produced in the above experiments was actually derived from DHA rather than by a possible stimulating effect of DHA on the endogenous processes, DHA- $1,3-C^{1+}$ was then used in place of nonradioactive DHA. Four times the usual amount incubation mixture was incubated with $4.4 \mathrm{mg}$. of DHA-1, 3-C $\mathrm{C}^{14}(0.3 \mu \mathrm{c}$.) that was dissolved in 0.1 $\mathrm{ml}$. of water. ATP was omitted to allow optimum formation of lactate in accordance with the results of the above experiments. Metabolic activity in 3 separate tubes was stopped at 0,10 and 20 minutes from the time of addition of DHA by adding $9 \mathrm{ml}$. of boiling ethanol. The mixture was chilled and centrifuged. The supernatant was combined with the 20 per cent ethanol washing of the residue and the solvent was removed under reduced pressure. Rcsidue from the alcoholic extract was transferred to filter paper for two-dimensional chromatography. A control experiment was carried out with lactate-1-C $\mathrm{C}^{14}$ in place of DHA-1, 3- $\mathrm{C}^{14}$. The film from the 0-minute incubation showed a single spot due to DHA; the 10-and 20-minute incubations showed two spots each, one corresponding to DHA and the other to lactic acid. From the chromatogram of the 20 -minute incubation the spot assumed to be lactic acid was eluted with 70 per cent ethanol. In further one-dimensional chromatography the radioactivity from the extract coincided with the lactic acid spot after development in butanol-acetic acid or ethanol-ammonia.

On the basis of the lactate-1-C ${ }^{1+}$ formation, experiments were carried out to iclentify other intermediate(s) of DHA metabolism. The relatively lower rate of conversion of DHA to lactate when ATP was added to the incubaltion mixture suggested a possible accumulation of intermediates under thesp conditions. This possibility was investigated. Incubation was stopped with boiling ethanol at 10 minutes after addition of DHA and the alcoholic extract was concentrated and subjected to two-dimensional chromatography as described above. The paper was sprayed with aniline-phthalic acid reagent to visualize the intermediates. Two distinct spots were observed-a light brown one indentical with pure DHA and a dark brown one corresponding to known DHA phosphate sample. When this experiment was repeated with and without the addition of NAD to the incubation mixture, no visible difference was noted. This experiment was again repeated with DHA-1, 3-C ${ }^{1+4}$, the ATP was added to the incubation mixture. Samples were removed at 0,10 and 20 minutes and the reaction was stopped with boiling ethanol. Spots corresponding to DHA. DHA phosphate and lactic acid were observed as predicted on 
Table 4.-Effect of Purification Procedures on Enzymic Activities

\begin{tabular}{ccc}
\hline Praparation & $\begin{array}{c}\text { Glycerokinase } \\
\text { units/mg. protein }\end{array}$ & $\begin{array}{c}\text { DHA Kinas } \\
\text { units } / \text { mg. protein }\end{array}$ \\
\hline $\begin{array}{l}\text { Whole homogenate } \\
\text { pH 5.1 soluble fraction } \\
\begin{array}{c}\text { Precipitate from 47\% } \\
\text { saturation with am- } \\
\text { monium sulfate }\end{array}\end{array}$ & 1.64 & 0.71 \\
$\begin{array}{c}\text { Supernatant after heat } \\
\text { treatment }\end{array}$ & 3.38 & 0.32 \\
\hline
\end{tabular}

1 unit $-0.1 \mu$ mole substrate phosphorylated $/$ hour $/ \mathrm{mg}$. protein at $37 \mathrm{C}$.

the x-ray film after a 7-day exposure. Subsequent to the autoradiography, spraying of the paper chromatogram with aniline-phthalic acid reagent revealed the DHA and the DHA phosphate spot. Their locations were identical with those of the autoradiography.

Comparison with previously described preparations: Since preparations of rat liver have been reported to phosphorylate DHA as well as glycerol or glyceraldehyde, ${ }^{8-10}$ the effect of procedures of preparation on the specific activity for DHA and other substrates was compared. In table 4, the results show that activity for the phosphorylation as DHA as measured by our method can be separated from the glycerokinase activity." When the homogenate from rat liver was dialyzed under various conditions, including one that has been described for a preparation which phosphorylated trioses ${ }^{10}$ the product was entirely inactive for the phosphorylation of DHA.

Other observations: The effect of DHA on the production of $\mathrm{CO}_{2}$ in liver homogenate was observed in a Conway diffusion cell which contained 2.5 times the usual amount of incubation mixture in the outer chamber. The $\mathrm{CO}_{2}$ produced in 20 minutes was determined titrimetrically. The amounts of $\mathrm{CO}_{2}$ produced with and without the addition of $20 \mu$ moles of DHA were 3.26 and $5.43 \mu$ moles, respectively. Thus, in vitro DHA seens to have an inhibitory effect on respiration of the homogenate.

Observation of the absorbance of complete incubation mixtures with liver extract at $340 \mathrm{~m} \mu$ in a spectrophotometer with the cuvette maintained at 37 C. showed no increase in absorbance due to net NADH formation. When NADH was used in the incubation mixture in place of NAD only a slow decrease in absorbance was observed.

\section{Discussion}

In this study, the identification of DHA phosphate as a principal intermediate indicates conclusively that the metabolism of DHA in liver starts with phosphorylation and thereupon follows the steps of the Embden-Meyerhof scheme. In the in vitro experiments with liver extracts, lactic acid is shown to be the major product, resolving the contradiction in earlier work ${ }^{3-5}$ and supporting more recent data on another tissue. ${ }^{00}$ In the intact rat, our previous work $^{2}$ showed divergent metabolic end products that are consistent with the known glycolytic pathway. This was indicated by the formation of radio- 
active respiratory $\mathrm{CO}_{2}$, blood glucose, and the labeling of the carbon atoms of the liver glycogen from injected DHA-1, 3-C ${ }^{14}$. As necessary corollary to the preliminary phosphorylation of DHA, there must be present in the rat liver a DHA kinase. This is consistent with our present data.

Lindberg, using dialyzed homogenate of rabbit kidney cortex in incubation medium containing ATP, Mg, NAD and $174 \mu$ moles of $\mathrm{NaF}$ in a total volume of $2.3 \mathrm{ml}$., was able to demonstrate uptake of $\mathrm{O}_{22}$ and inorganic orthophosphate due to DHA. He further showed the product not to be alkali-labile, thus suggesting that it was fructose diphosphate. ${ }^{7}$ Our data shows that $\mathrm{NaF}$ at that concentration would completely inhibit phosphorylation of DHA and that without $\mathrm{NaF}$, the product is essentially lactic acid. This discrepancy could be explained on the basis of difference in tissue, animal, or the preparation of tissue. Hers and Kusaka, working with partially purified homogenate of guinea pig liver described a triokinase which phosphorylates D-glyceraldehyde and DHA. ${ }^{8}$ The glycerokinase obtained by Bublitz and Kennedy from rat liver however, phosphorylate L-glyceraldehyde and DHA. ${ }^{9}$ Now that we have demonstrated the difference between this glycerokinase and a DHA kinase of the same tissue, the occurrence of several distinct enzymes with common activity for DHA seems likely. Possibly Cardini was reporting yet another enzyme from the liver of the fasting rat. ${ }^{10}$ Unfortunately, none of these preparations is purified sufficiently to allow precise characterization. One related enzyme that has been highly purified is the glycerokinase of pigeon liver. ${ }^{21}$

It should be noted that our procedure for the determination of DHA does not include DHA phosphate; therefore, the rate of DHA disappearance as measured is due to DHA conversion alone.

\section{REFERENCES}

1. Cori, C. F., and Cori, G. T.: The fate of sugar in animal body. VIII. The influence of insulin on the utilization of glucose, fructose and dihydroxyacetone. J. Biol. Chem. 76:755, 1928.

2. Tsao, M. U., Bernstein, I. A., and Lowrey, G. H.: Metabolism of $\mathrm{C}^{14}$-dihydroxyacetone in the intact rat. Metabolism 11:465, 1962.

3. Embden, G., Baldes, K., and Schmitz, E.: Uber den Chemismus der Milchsäurebildung aus Trauben zucker im Tierkörper. Biochem. Ztschr. 45:108, 1912.

4. Locbel, R. O.: Beiträge zur Atmung und Glykolyze tierischer Gewebe. Biochem. Ztschr. 161:219, 1925.

5. Meyerhof, O., and Lohman, K.: Atmung und Kohlenhydratumsatz tierischer Gewebe 1. Biochem. Ztschr. 171:381, 1926.

6. Imanaga, H.: Über die Kondensation von Triosen zu Hexosen in der Leber. Biochem. Ztschr. 294:342, 1937.

7. Lindberg, O.: Phosphorylation by glyceraldehyde, glyceric acid and dihydroxyacetone by kidney extracts. Biochim. Biophys. Acta 7:349, 1951 .

8. Hers, H. G., and Kusaka, T.: Le metaholisme du fructose-1-phosphate dins le foic. Biochim. Biophys. Acta 11: $427,1953$.

9. Bublitz, C., and Kennedy, E. P.: Synthesis of phosphatides in isolated mitochondria. III. The enzymic phosphorylation of glycerol. J. Biol. Chem. 211:951, 1954.

10. Cardini, C. E.: Fosforilación de lats triosas en el higado. Acta Bioquím. $2: 30,1953$.

11. Tsao, M. U., and Schwartz, E. L.: Microdetermination of dihydroxyacetone in biological fluids. Anal. Biochem. 2: 107, 1961. 
12. -, and Schwartz, E. L.: A simple method for estimating dihydroxyacetone (or glyceraldehyde). Anal.. Biochem. 3:448, 1962.

13. - , - , and Lowrey, G, H.: Metabolism of dihydroxyacetone in the intact rat. Metabolism 11:456, 1962.

14. Hogeboom, G. H.: In Methods in Enzymology, vol. 1. S. P. Colowick, and N. O. Kaplan (eds.). New York, Academic Press, Inc. 1955, p. 16.

15. Barker, S. B., and Summerson, W. H.: The colorimetric determination of lactic acid in biological material. J. Biol. Chem. 138:535, 1941.

16. Kornberg, H. L.: The metabolism of $\mathrm{C}_{2}$ compounds in microorganisms. Biochem. J. 68:535, 1958.
17. Wood, T.: In: Chromatographic Techniques, vol. I. Smith (ed.) London, Wm. Heinemann Medical Books, Ltd. 1958, p. 207.

18. Partridge, S. M.: Aniline hydrogen phthalate as a spraying reagent for chromatography of sugars. Nature 164:443, 1949.

19. Conway, E. J.: Microdiffusion Analysis and Volumetric Error. New York, D. Van Nostrand Co., Inc., 1947, p. 189.

20. Mann, T., and White, I. G.: Glycerol metabolism by spermatozoa. Biochem. J. 65:634, 1957.

21. Wieland, O., and Suyter, M.: Glycerokinase: Isolieren und Eigenschaften des Enzymes. Biochem. Ztschr. 329: $320,1957$.

M. U. Tsao, Ph.D., Associate Professor of Biochemistry, The University of Michigan, Ann Arbor, Mich.

Susan J. T'eagan, B.S., Graduate Student, Duke University, Durham, N. C.

Pal E. Borondy, B.S., Assistant in Research, The University of Michigan, Ann Arbor, Mich.

James F. Hogg, Ph. D., Assistant Professor of Biochemistry, The University of Michigan, Ann Arbor, Mich. 